【Original Article】

\title{
Baxter and Cotnoir on Composition as Identity
}

Joongol Kim*

\section{【Subject Class】 Metaphysics}

【Keywords】 Mereology, Composition as Identity, loose identity, many-one identity, plural identity

【ABSTRACT】 This paper provides a critical examination of three related attempts to defend Composition as Identity (CI), namely the thesis that if some things compose something, then they are it. First, it will be argued against Donald Baxter's view of composition as 'loose identity' that by construing composition as strictly a many-many relation, the view trivializes $\mathrm{CI}$, and cannot be an option for the advocate of $\mathrm{CI}$ who takes composition as a genuine many-one relation. Second, it is argued against Baxter's modified view of composition as 'cross-count identity' that the 'are' in 'they are it' cannot be viewed as expressing cross-count identity. Lastly, it is argued against Aaron Cotnoir's view of composition as 'general identity' that it amounts to resorting back to Baxter's old view of composition as a many-many relation.

\footnotetext{
* Sungkyunkwan University
} 


\section{I . Introduction}

In Parts of Classes, Lewis $(1991,81)$ famously declared that "Mereology is ontologically innocent", despite the fact that he accepts a mereological principle that he (ibid., 74) calls "Unrestricted Composition", namely the principle that whenever there are some things $x x, 1)$ there is a "fusion" of $x x$, that is, a thing $y$ such that $x x$ compose $y$. He defends the ontological innocence of mereology thus:

To be sure, if we accept mereology, we are committed to the existence of all manner of mereological fusions. But given a prior commitment to cats, say, a commitment to cat-fusions is not a further commitment. The fusion is nothing over and above the cats that compose it. It just is them. They just are it.

The thesis that a fusion-henceforth, a (mereological) sum-is (identical with) its parts is what Lewis (ibid., 82) called Composition as Identity. This is often abbreviated in the literature as $\mathrm{CI}$ or CAI (see Baxter and Cotnoir 2014 for references), but in this paper 'CI' will be used as an acronym for Composition as Identity, reserving 'CAI' for a particular form of that thesis.

One natural reading of 'It just is them' and 'They just are it' is that the parts and their mereological sum are strictly identical in the Leibnizean sense of being indiscernible in any possible way whatever. This view might be called composition as strict identity, or CSI for short:

1) The variable $x x$ is a plural variable ranging over pluralities of objects in a given domain. For a quick introduction to plural variables, plural predicates, and plural quantification, see Yi 2006. 
CSI The parts and their sum are strictly identical.

However, Lewis $(1991,87)$ rejected CSI as indefensible, claiming that "we do not really have a generalized principle of indiscernibility of identicals" that can be applied to the parts and their sum:

What's true of the many is not exactly what's true of the one. After all they are many while it is one. The number of the many is six, as it might be, whereas the number of the fusion is one.

Since the parts are many and not one in number, and since the whole is one and not many, the parts and their sum are numerically distinguishable and hence cannot be strictly identical.2)

Yet, while rejecting CSI, Lewis retained the view that mereology is ontologically innocent. He $(1991,82)$ claimed that "compositionthe relation of part to whole, or, better, the many-one relation of many parts to their fusion-is like identity". In Lewis's view, the 'are' in "They just are it" expresses something similar to, albeit different from, genuine identity. Indeed, he (ibid., 84) comments that "So striking is this analogy that it is appropriate to mark it by speaking of mereological relations" such as composition "as kinds of identity". This view might be called composition as analogous to identity, or CAI for short:

CAI The relation of the parts to their sum is analogous to identity.

Lewis (ibid., 85-7) provides several points of analogy between composition and identity including ontological innocence ${ }^{3)}$ and

2) See Yi 1999, sect. II, and Sider 2007, sect. 3, for related discernibility arguments against CSI. 


\section{8 논문}

unrestricted composition, and argues that those analogies are strong enough to establish the ontological innocence of mereology. However, it remains doubtful whether this is the case (see Yi 1999, sects. III-IV, for discussion and references).

Since it appears that the parts and their sum are numerically discernible, which means that CSI should be rejected, and also since the alleged analogy between composition and identity seems too weak to ground the claim of ontological innocence of mereology, which means that CAI should be rejected as well, one might be tempted to defend mereology against the charge of ontological profligacy by abandoning the starting assumption that the relation of the parts to their sum is a many-one relation and insisting that it is rather a many-many relation. This revisionist account of composition is what Donald Baxter has proposed when he $(1988 \mathrm{~b}, 580-1)$ wrote that "The whole, then, is just the parts counted loosely" and that "It is strictly a multitude and loosely a single thing". This view will be referred to as composition as loose identity, or CLI for short:

CLI The parts and their sum are loosely identical.

If CLI is true, and so strictly there is no single thing that the parts together compose, then the worry of ontological excess could be avoided.

However, this paper argues that CLI and two other related attempts to defend CI all fail. To that end, it will be argued first

3) As Yi $(1999,159$ n14) points out, this inclusion of ontological innocence among the points of analogy between composition and identity makes Lewis's defense of the ontological innocence of mereology vulnerable to the charge of begging the question. 
that Baxter's CLI trivializes CI, and cannot be an option for the advocate of $\mathrm{CI}$ who takes composition as a genuine many-one relation (section 2). Next, it is argued against Baxter's (1988a) modified account of $\mathrm{CI}$ in terms of the notion of cross-count identity that the 'are' in 'the parts are the whole' cannot be viewed as expressing cross-count identity (section 3). Lastly, it is argued against Aaron Cotnoir's (2013) recent refinement of Baxter's account in terms of the notion of general identity that it amounts to resorting back to Baxter's old view of composition as a many-many relation (section 4). The Conclusion section briefly points to where the next steps might go if one still wants to hold on to $\mathrm{CI}$.

\section{Composition as Loose Identity}

According to Baxter, although the parts, taken individually, are distinct from their sum, they are, taken collectively, identical with it. He $(1988 b, 578)$ calls this view the "Identity view", and supports it by considering the following case (ibid., 579):

Suppose a man owned some land which he divides into six parcels. Overcome with enthusiasm for [the denial of the Identity view] he might try to perpetrate the following scam. He sells off the six parcels while retaining ownership of the whole. That way he gets some cash while hanging on to his land. Suppose the six buyers of the parcels argue that they jointly own the whole and the original owner now owns nothing. Their argument seems right. But it suggests that the whole was not a seventh thing.

It seems indeed that the whole land was not a seventh thing over 


\section{0 논문}

and above the six parcels of land. It would be a punishable scam if he attempted to sell the whole land to one buyer after having sold off the six parcels of land individually to six different buyers. Thus, although each of the six parcels is distinct from the whole, it would seem that collectively they are just the same thing as the whole.

However, when confronted with the question of "How can a whole be a single thing and yet be identical with a multitude?"this is the question that forced Lewis to reject CSI-Baxter (1988b, 580) appeals to what he calls "the Butler view of identity", according to which "on strict standards for counting the parts are many and on loose standards they are one". In other words, on the Butler view, the whole is in fact many on strict standards, although, for various practical purposes, we often adopt loose standards and count it as one. Thus, Baxter's (ibid., 580-1) answer to the above question is that "The whole, then, is just the parts counted loosely". That is, a whole can be a single thing and yet be identical with a multitude because "It is strictly a multitude and loosely a single thing" (ibid., 581). There is no contradiction in saying this, unlike saying that the whole is strictly both a multitude and a single thing.

Unfortunately, Baxter's view of composition as loose identity, CLI, is a Pyhrric defense of Composition as Identity, CI: the whole is identical (in the loose sense) with the parts only because, really and strictly, it is not one thing but many things. Since the parts are many, and since, for Baxter, the whole is also, strictly, many, it is no surprise that they can be identical with 'it'. However, this attempt to save CI by construing composition as a many-many relation trivializes $\mathrm{CI}$. If $\mathrm{CI}$ is to be a nontrivial thesis, 
composition must be a relation between many things as such and one thing as such. For recall that Lewis's original motivation for CI was to argue that mereology is ontologically innocent despite Unrestricted Composition, namely the principle that whenever there are some things $x x$, there is a thing $y$ such that $x x$ compose $y$, where the singular variable $y$ is supposed to range over single, individual objects in the domain of discourse. That is, Unrestricted Composition says that any given two or more things compose a single individual thing which is their sum. And as an individual thing, the sum is, really and strictly, one in number, and it is because of this fact that Lewis had to settle for CAI-the view that composition is merely akin to identity -instead of CSI, for the parts are many and not one, and so, by Leibniz's law, cannot be identical with their sum. Therefore, Baxter's way out of the difficulty facing the advocate of Unrestricted Composition is not open to her.

To put it differently, Baxter rejects mereology in favor of an alternative view of the relationship of parts to whole. Indeed, he (1988b, 578) writes that "The mereological view is currently so firmly entrenched that it makes it hard to see the Butler view as a viable alternative". Thus, given that his (ibid.) express purpose is "To dislodge the entrenched view, or at least to make room for a competitor", his Identity view of parts and whole should be regarded, pace Lewis $(1991,84 \mathrm{n} 12)$, more as an attack on (mereological) Composition as Identity than as a defense of it. On the Identity view, there is no individual thing $y$ such that some things $x x$ together compose $y$, and hence the relation of composition-and a fortiori, Composition as Identity-must be, strictly, an illusion. 


\section{2 논문}

Baxter (1988b, 578) might reply that the Identity view is not a form of mereological nihilism - namely the view that there are no objects with proper parts (for discussion, see van Inwagen 1990, 72-3) - and "is not to deny the existence of the whole" but "merely to deny the additional existence of the whole". However, it is misleading to characterize the Identity view as admitting the existence of the whole. If the whole really exists, then since it is distinct from any one of its parts-for example, the whole land is not one of the six parcels of land - there has to be some one thing distinct from each of those parts. But, according to Baxter (ibid.), "there is no one thing distinct from each of the parts which is the whole", and "Rather the whole is simply the many parts with their distinctness from each other not mattering"; or, as quoted above, "The whole, then, is just the parts counted loosely" (ibid., 580-81). This means that when the parts are strictly counted, the whole does not exist. It is no use insisting that when they are loosely counted, it does exist. For the question of whether something exists or not is to be decided by what things are really and strictly like, not by loose standards that blur the finer structures of reality. So, inasmuch as the Identity view is unable to countenance the strict existence of the whole, it cannot be regarded as providing a defense of Composition as Identity.

\section{Composition as Cross-Count Identity}

In another paper, Baxter seems to renounce the distinction between strict and loose standards of counting, and instead to adopt a relativist attitude toward them. He (1988a, 193) claims that 
"identity (in the familiar sense), number, and existence are relative to what I call "counts'". Note that existence is said to be relative to ways of counting. For Baxter (ibid.), "There is no one count of what exist, there are many", and it is merely that "Some counts are better than others depending on interest or purpose". To illustrate, when the landowner considers selling his land off to six different buyers, a useful count of what exist would be that in which the six parcels of land exist; in another count of what exist which might be useful for, say, taxation - the six parcels of land taxed individually might result in higher taxes - the whole land exists. "But not both a whole and its various parts are in a given count", which means that "what exists is relative to count" (ibid., 201). Since existence is relative to counts, it is only natural that identity and number should be relative to counts, too. For only the existing things can bear the relation of identity to one another and possess such properties as being one and being many.

Since the parts which exist relative to a way of counting cannot be identical with the whole which, relative to the same count, does not exist, it might seem that Baxter's relativism is incompatible with Composition as Identity. However, Baxter (1988a, 193) argues that his relativist strategy can help to make sense of CI:

Within a count it is never the case that many things are one thing. The familiar version of identity rules within counts. But I introduce a new sort of identity to hold between counts - call it 'cross-count identity'. In addition to one thing in one count being cross-count identical with one thing in another, many things in one count can be cross-count identical with one thing in another.

So it turns out that the old distinction between strict and loose identity was not rejected in its entirety but has been refashioned 


\section{4 논문}

into a new distinction between "identity (in the familiar sense)" and "cross-count identity". In this new scheme of things, identity, formerly known as strict identity, holds only among those things to which the same standard of counting is applied; those things which are counted using different standards - such as the six parcels of land and one whole land - can stand in the relation of cross-count identity formerly known as loose identity.

This relativist approach to CI might seem to avoid the above objection leveled against the Identity view-namely that if the whole is just the parts counted loosely, then the whole does not really exist. On the present approach, the whole does exist (in a count), albeit not in the count in which its parts exist; in other words, the whole is really one thing (relative to the count in which it exists), and not just many things counted loosely. So the relation of composition seems to be reinstated as a genuine many-one relation, and $\mathrm{CI}$ as a thesis involving genuine many-one identity. These results are due to making all counts equal in the sense that there are many equally legitimate counts of what exist, none of which is more strict or loose than any others (although some counts are better or worse depending on "the interests or purposes of people" (ibid., 210)). That is the very point of Baxter's (ibid., 193) claim that "I make sense of many-one identity by positing that identity (in the familiar sense), number, and existence are relative to what I call 'counts'".

However, again, it seems misleading to talk of 'many-one identity' when the relation of identity involved is not identity in the familiar sense but cross-count identity. If the parts which are many are not identical but cross-count identical with the whole which is one, then it cannot be said simply, using the 'are' of many-one identity, 
that they are it. To see why, note Baxter's (1988a, 209) remark that "On my account the plural form refers to things in one count, the singular form refers to one thing in another count, and the 'are' expresses many-one identity". This means that on his relativist account, the words 'they' and 'it' in 'they are it' involve ellipsis and mean, respectively, 'they in count $c$ ', or 'they' ${ }_{c}$ ' for short, and 'it in count $d$ ', or ' it $_{d}$ ', for some suitable counts $c$ and $d$, and that the 'are' is understood to mean 'are cross-count identical with'. Thus, in Baxter's view, CI, namely the thesis that

(1) If some things compose something, then they are it

would be equivalent to saying that for some suitable counts $c$ and $d$,

(2) If some things compose something, then they $y_{c}$ are cross-count identical with it $_{d}$.

But (2) makes no sense: since the expressions 'some things' and 'something' in the antecedent do not refer relative to counts, 'they' ${ }_{c}$ ' and ' $\mathrm{it}_{d}$ ' in the consequent fail to refer back to them. The reason that 'some things' and 'something' in the antecedent do not mean the same as 'some things in count c' and 'something in count $d$ ' can be seen from the fact that the predicate 'compose' can be analyzed, using the plural variable $x x$ and the predicate 'overlaps' in the sense of 'has a part in common with', as follows (Lewis 1991, 73; Yi 2014, 183):

(3) $x x$ compose $y=_{\mathrm{df}}$ any one of $x x$ is part of $y$, and any part of $y$ overlaps one of $x x$. 


\section{6 논문}

So, if some things, say $a a$, compose something, $b$, then any one of $a a$ is part of $b$. Note that by the meaning of 'is part of', something $x$ that is part of $y$ cannot exist unless $y$ exists. Thus, since any one of $a a$ is part of $b$, it follows that $a a$ cannot exist unless $b$ exists, and hence that $a a$ can exist only in the count in which $b$ exists. This means that $a a$ and $b$ do not exist relative to counts, which in turn means that the ' $x x$ ' and ' $y$ ' in ' $x x$ compose $y$ ' cannot be construed as involving ellipsis and meaning ' $x x$ in $c$ ' and ' $y$ in $d$ ' for two distinct counts $c$ and $d$. And if this is right, then 'some things' and 'something' in the antecedent of (2) cannot be relativized to counts. Hence, (2) is not a well-formed sentence.

The upshot of these considerations is that the relation of many-one identity expressed by the 'are' in the consequent of (1) cannot be cross-count identity. If some things compose something, then since the parts cannot exist unless their sum exists, the relation of many-one identity involved in CI has to be identity in the familiar sense. Thus, Baxter's attempt to make sense of CI in terms of cross-count identity fails.

\section{Composition as General Identity}

Cotnoir (2013) has presented a refined version of Baxter's view of composition as cross-count identity by introducing the notion of 'general identity'. Suppose given a domain $D$ of objects considered as the 'atoms' of $D$. A concept $F$ - a way of counting-is supposed to divide $D$ exhaustively and disjointly into $F \mathrm{~s}$, each of which is a plurality of atoms of $D$. Then a plurality of $F \mathrm{~s}, x x$, are defined to be generally identical with a plurality of $G \mathrm{~s}, y y$, just in case the 
atoms of $D$ that make up the $x x$ are the atoms that make up the $y y$, where the 'are' means the standard relation of plural identity.4) To illustrate, consider a domain $Q$ whose atoms are the four quadrants of a circle $c$. $Q$ can be counted in an exhaustive and disjoint manner in four different ways: as four quadrants (clockwise from top left, $q_{1}-q_{4}$ ), two vertical semicircles ( $t$ and $b$ ), two horizontal semicircles ( $l$ and $r$ ), and one circle $(c)$. Then, $t$ and $b$ are generally identical with $l$ and $r$ because the atoms that make up $t$ and $b$, namely $q_{1}-q_{4}$, are the atoms that make up $l$ and $r$. This is a case of many-many general identity. For a case of many-one general identity, notice that $q_{1}$ and $q_{2}$ are the atoms that make up $t$. So the two upper quadrants are generally identical with the top semicircle.

Cotnoir's theory of general identity improves on Baxter's view of composition as cross-count identity in that it avoids the difficulty that the latter had in making sense of CI, namely the thesis that

(1) If some things compose something, then they are it.

Recall that in Baxter's view, even existence - and hence referenceis relative to counts, and so the pronouns 'they' and 'it' in 'they are it' refer to some things in one count and something in another count, respectively. For instance, the plural term ' $t$ and $b$ ' would refer to the two vertical semicircles which exist in one count, and the singular term ' $c$ ' to the circle which exists in another count. This causes trouble for Baxter's view, because, as noted above, the expressions 'some things' and 'something' in the antecedent of (1) cannot be viewed as having reference relative to counts. By

4) That is, $x x$ are $y y=_{\mathrm{df}}$ anything $z$ is one of $x x$ iff $z$ is one of $y y$. 


\section{8 논문}

contrast, in Cotnoir's framework for general identity, existence and reference are not relative to counts. Cotnoir (2013, 303) stipulates singular and plural terms to range over pluralities of atoms and pluralities of pluralities of atoms, respectively.5) Thus, the singular term ' $c$ ' refers to the atoms that make up $c$, namely $q_{1}, q_{2}, q_{3}$, and $q_{4}$; the plural term ' $t$ and $b$ ' refers to two pluralities of atoms one of which is the atoms ' $t$ ' refers to, namely $q_{1}$ and $q_{2}$, and the other of which is the atoms ' $b$ ' refers to, namely $q_{3}$ and $q_{4}$. Since reference to non- atomic things is reduced in that fashion to reference to atoms, and since the atoms exist independently of ways of counting, reference should be independent of counts. So, in Cotnoir's framework, the sentence ' $t$ and $b$ are $c$ ' would be true - literally, not in the sense of ' $t$ and $b$ in one count are $c$ in another count' - if the 'are' is understood to mean general identity.

However, on reflection, it can be seen that this apparent advantage of Cotnoir's theory over Baxter's is not real. In Cotnoir's theory, many-one general identity can hold only because syntactically singular terms are semantically plural. For instance, ' $t$ and $b$ are $c$ ' is true only because the singular term ' $c$ ' refers to the quadrants, $q_{1}-q_{4}$. That is, the so-called 'many-one' general identity is really a kind of many-many identity.

Moreover, since Cotnoir's thesis of composition as general identity says that

(4) If some things compose something, then they are generally identical with it

5) Cotnoir $(2013,301)$ himself avoids talk of hyperplurals such as 'pluralities of pluralities of atoms', and instead provides a set-theoretic semantics for terms. 
and since the 'it' in the consequent of (4) is semantically plural, the 'something' in the antecedent has to be semantically plural as well. This means that the relation of composition cannot be analyzed in the standard manner, that is, as in (3) in terms of the predicate 'is part of' which requires a semantically singular term in its second argument place. Cotnoir $(2013,306)$ provides an alternative definition of composition as follows:

(5) $x x$ compose $y==_{\mathrm{df}} x x$ are parts of $y$, and $y$ is covered by $x x$

where ' $x x$ are parts of $y$ ' and ' $y$ is covered by $x x$ ' mean, respectively, that the atoms that make up $x x$ are among the atoms that make up $y$ and that the atoms that make up $y$ are among the atoms that make up $\left.x x^{6}{ }^{6}\right)$ It is clear from these definitions that if some things compose something, then the singular 'something' refers to a plurality of atoms, and so is semantically plural. Thus, in Cotnoir's theory, composition is really a many-many relation, although the corresponding predicate, 'compose', requires a grammatically singular term in its second argument place.

One cannot miss the irony: Cotnoir's attempted improvement on Baxter's view of composition as cross-count identity has recourse to Baxter's original view of composition as strictly a many-many relation. The wheel has turned full circle. The idea that the parts are cross-count identical with the whole allowed Baxter to insist that there is really some one thing such that they are identical with it. The only problem was that they could not be viewed as existing in the count in which it exists. Cotnoir's trick is to

6) Here the among relation is understood as follows: $x x$ are among $y y=_{\mathrm{df}}$ for anything $z$, if $z$ is one of $x x$, then $z$ is one of $y y$. 


\section{0 논문}

stipulate singular and plural terms to range over pluralities of atoms and pluralities of those pluralities, respectively, despite their putative reference to individual objects and their pluralities, thus bypassing the thorny issue of relative existence of parts and whole. However, the trick amounts to rejecting the many-one relation of composition as a mere syntactic phenomenon and replacing it with a many-many relation at the atomic level of reality. So Cotnoir's view of composition as general identity is subject to the same objection as Baxter's thesis of CLI: it is not so much a defense of $\mathrm{CI}$ as an attack on it, and cannot be an option for the advocate of CI who takes mereological composition seriously, that is, as a genuine many-one relation.

\section{Conclusion}

If CLI and its ilk all fail to provide a satisfactory defense of CI, then how else could one proceed if one still wants to respect and preserve the intuition that the whole is nothing over and above its parts and so must be identical with them?

One possible solution that has been proposed by some writers (see, among others, Bohn 2009 and 2014, and Wallace 2011a and $2011 \mathrm{~b}$ ) is to leave existence and identity as absolute and to restrict relativity to a small number of problematic properties and relations such as the properties of being one and being many and the one of relation. On this approach, which might be called moderate relativism, the four quadrants are identical with the circle: they are absolutely the same portion of reality as it. And the objection that the same portion of reality cannot be both one and many in 
number is addressed by saying that the same portion of reality is four relative to the concept quadrant and one relative to the concept circle.

One problem with moderate relativism is that it requires major changes in plural logic (see Sider 2007, 68-9, and Carrara and Lando 2017). Numerical predicates of the form 'to be $n$ (in number)' can be defined in terms of the plural predicate 'is one of' (see Yi 2006, 246, and 2014, 175). For instance, the predicate 'to be one' can be defined as follows:

(6) $x x$ are one $=_{\mathrm{df}}$ something that is one of $x x$ is identical with anything that is one of $x x$.

Thus, in order to relativize numerical predicates to concepts, it would be necessary to construe the dyadic predicate 'is one of' as a case of ellipsis, that is, as a triadic predicate with an omitted argument place that admits terms for concepts:

(7) $x x$ are one relative to $F==_{\mathrm{df}}$ something that is one of $x x$ relative to $F$ is identical with anything that is one of $x x$ relative to $F$.

To illustrate, since the quadrants are one relative to the concept circle, it follows by (7) that

(8) Something that is one of the quadrants relative to the concept circle is identical with anything that is one of quadrants relative to the concept circle. 


\section{2 논문}

However, it is questionable whether the predicate 'is one of' so used expresses the intuitive notion of the one of relation in a correct manner. For one might well insist that it is a conceptual truth that

(9) $x$ is one of $y_{1}, \ldots, y_{\mathrm{n}}$ if and only if $x=y_{1}$ or, $\ldots$, or $x=y_{\mathrm{n}}{ }^{7)}$

If so, then since nothing other than each of the four quadrants is one of them, the whole circle cannot be one of them which are its proper parts.

Thus, if, pace Baxter, the relation of composition is to be viewed as a genuine many-one relation, and also if the predicate 'is one of' is to be taken at face value as a dyadic predicate, then it would seem that a defense of CI requires showing how it is possible for many things as such to be identical with one thing as such and so to have all and only the properties that the latter has, including the numerical property of being one (absolutely). In other words, a defense of CI would need to take the form of a defense of CSI-namely, the widely dismissed thesis of composition as strict identity (see Kim forthcoming, esp. sects. 3-4, for a defense of CSI against the discernibility arguments mentioned in the Introduction section). ${ }^{8)}$

투 고 일: 2019. 05. 26

심사완료일: 2019. 06. 20

게재확정일: 2019. 08. 13

Joongol Kim

Sungkyunkwan University

7) This is the principle that Sider $(2007,58)$ calls Lists.

8) Thanks are due to the three anonymous reviewers for this journal for helpful comments. 


\section{References}

Baxter, D. L.: 1988a, 'Many-One Identity'. Philosophical Papers 17(3), 193-216.

Baxter, D. L. M.: 1988b, 'Identity in the Loose and Popular Sense'. Mind 97, 575-582.

Bohn, E.: 2009, 'Composition as Identity: a Study in Ontology and Philosophical Logic'. Ph.D. thesis, University of Massachusetts Amherst. https://scholarworks.umass.edu/open_access_dissertations/92.

Bohn, E. D.: 2014, 'Unrestricted Composition as Identity'. In (Cotnoir and Baxter, 2014), pp. 143-165.

Carrara, M. and G. Lando: 2017, 'Composition and Relative Counting'. dialectica 71(4), 489-529.

Cotnoir, A.: 2013, 'Composition as General Identity'. In: K. Bennett and D. W. Zimmerman (eds.): Oxford Studies in Metaphysics, Volume 8. Oxford: Oxford University Press, pp. 294-322.

Cotnoir, A. J. and D. L. M. Baxter (eds.): 2014, Composition as Identity. Oxford: Oxford University Press.

Kim, J.: forthcoming, 'Plural Identity'. Philosophy and Phenomenological Research. doi: 10.1111/phpr.12626.

Lewis, D.: 1991, Parts of Classes. Oxford: Basil Blackwell.

Wallace, M.: 2011a, 'Composition as Identity: Part 1'. Philosophy Compass 6(11), 804-816.

Wallace, M.: 2011b, 'Composition as Identity: Part 2'. Philosophy Compass 6(11), 817-827.

Yi, B.-U.: 1999, 'Is Mereology Ontologically Innocent?'. Philosophical Studies 93, 141-160.

Yi, B.-U.: 2006, 'The Logic and Meaning of Plurals. Part II'. Journal of Philosophical Logic 35, 239-288. 


\section{4 논문}

Yi, B.-U.: 2014, 'Is there a Plural Object?'. In (Cotnoir and Baxter, 2014), pp. 169-191. 
국문요약

\section{“동일성으로서의 구성”에 관한 백스터와 코트너의 이론}

\section{김 준 걸*}

본 논문의 목적은 “동일성으로서의 구성”-즉, "만약 어떤 것들이 어떤 것을 구성한다면, 그들이 그것이다"라는 논제-을 옹호하려는 세 가지 관련된 시도를 비판적으로 검토하는 것이다. 이를 위해 첫째, 구성을 '느 슨한 동일성'으로 보는 도널드 백스터의 견해에 반하여, 이 견해가 구성 을 다대다(多對多) 관계로 해석함으로써 위의 논제를 사소하게 만들고, 따라서 구성을 진정한 다대일(多對一) 관계로 여기면서도 그 논제를 옹 호하고자 하는 이에게는 열려 있는 선택지가 될 수 없음을 논증한다. 둘 째, 구성을 '셈들 간의 횡적 동일성'으로 보는 백스터의 수정된 견해에 반하여, '그들이 그것이다'에서의 '이다'는 셈들 간의 횡적 동일성을 표 현한다고 볼 수 없음을 논증한다. 마지막으로, 구성을 '일반적 동일성'으 로 보는 아론 코트너의 견해에 반하여, 이 견해가 구성을 다대다 관계로 보는 백스터의 원래 견해로 되돌아가는 것임을 논증한다.

\section{주제분류: 형이상학}

주요어: 부분론, 동일성으로서의 구성, 느슨한 동일성, 다대일 동일성, 복수적 동일성 
